\title{
RECUPERACIÓN DE ACTIVOS ILÍCITOS: ANÁLISIS JURÍDICO DE LA LEGISLACIÓN INTERNACIONAL Y NACIONAL APLICABLE PARA MÉXICO.
}

\author{
Germán Guillén López ${ }^{1}$ \\ Manuel Alejandro Encinas Islas ${ }^{2}$ \\ “¡Contra la injusticia y la impunidad! Ni perdón ni olvido.”
}

Bertolt Brecht

Sumario: I. Consideraciones previas. II. Normatividad internacional. III. Marco jurídico mexicano.IV. Aplicación en el combate a la corrupción.V. Conclusiones. VI. Bibliografía y fuentes consultadas.

\section{Resumen}

El presente artículo aborda una de las problemáticas más emergentes de la justicia penal: la recuperación de activos ilícitos. La impunidad, la ausencia de consecuencias penales para ciertos sectores encumbrados de nuestra sociedad y por ende, la escasez de sentencias condenatorias, así como la poca frecuencia de logros en este rubro dan un espacio propicio para analizar la plataforma jurídica en la que, en nuestro país, maniobran los operadores jurídicos por lo que toca a la recuperación de activos ilícitos. Primeramente, se hace una breve introducción a elementos preliminares de los que resulta necesario contar con antecedentes. Posteriormente, se hace una revisión a las principales directrices de las convenciones internacionales vinculantes que rigen en la materia. Después, se hace un estudio de disposiciones y figuras que contempla para el tratamiento penal de estos supuestos el marco jurídico nacional. Previo a la finalización de la publicación se hace una aproximación a la aplicación de estos mecanismos en el escenario del combate a la corrupción. Finalmente, se presenta un apartado de conclusiones generadas durante la elaboración de la presente publicación.

Palabras clave: activos, ilícitos, recuperación, decomiso, abandono, extinción, dominio, corrupción.

\footnotetext{
${ }^{1}$ Docente Investigador de Tiempo Completo del Departamento de Derecho de la DCS,URC,UNISON

2 Estudiante de la Licenciatura en Derecho de la Universidad de Sonora
} 


\title{
RECOVERY OF ILLICIT ASSETS: LEGAL ANALYSIS OF INTERNATIONAL AND NATIONAL LEGISLATION APPLICABLE TO MEXICO.
}

\begin{abstract}
:
The present article addresses one of the most emerging issues in criminal justice: recovery of ilicit assets. Impunity, the absence of criminal consequences for certain high-ranking sectors of our society and, therefore, the scarcity of condemnatory sentences, as well as the infrequency of achievements in this area provide an appropriate space for analyzing the legal platform in which, in our country, legal practitioners operate with regard to the recovery of illicit assets. Firstly, a brief introduction is given to preliminary elements for which background information is required. Subsequently, a revision is made to the main guidelines of the binding international conventions governing the matter. Afterwards, a study is made of provisions and figures that the national legal framework contemplates for the criminal treatment of these cases. Prior to the finalization of the paper an approximation is made regarding the application of these mechanisms in the scenery of the fight against corruption. Finally, a section of conclusions generated during the preparation of this publication are presented.
\end{abstract}

Keywords: illicit assets, recovery, confiscation, abandonment, extinction, domain, corruption.

\section{Consideraciones previas}

Desde determinada perspectiva, se podría interpretar claridad que entre los principales elementos que debe atender el derecho penal están sin duda: $1^{\circ}$ ) sanción al delincuente; $2^{\circ}$ ) reparación del daño a la víctima u ofendido. En este orden de ideas, estos elementos tendrían que ser cubiertos, en cada uno de sus extremos, si se pretende alcanzar con plenitud el ideal que establece la justicia penal.

De dichos elementos nos centraremos en la reparación del daño, como principio fundamental de justicia para las víctimas del delito. Según la Resolución 
$40 / 34^{3}$ de la Organización de las Naciones Unidas "el resarcimiento comprenderá la devolución de los bienes o el pago por los daños o pérdida sufridos, el reembolso de los gastos realizados como consecuencia de la victimización, la prestación de servicios y restitución de derechos".

Además de ofrecernos este concepto, dicha resolución establece el compromiso de los gobiernos por revisar su normativa interna a fin de considerar el resarcimiento como una sentencia posible en materia penal, derivada de su obligación de garantizar el efectivo cumplimiento de la reparación del daño como consecuencia del delito.

Dicho lo anterior, tendría que entenderse la devolución de bienes como componente de una sentencia que contemple la reparación del daño en delitos que generan afectación al patrimonio, sea éste del particular o del Estado, siempre que tal devolución sea jurídica y materialmente posible. Es decir, una reparación del daño que se diga justa lleva aparejada la recuperación del producto del delito en beneficio de la víctima u ofendido, siempre que esto sea posible.

En el caso de la afectación al patrimonio del Estado es importante precisar que el daño repercute la sociedad en su conjunto. Algunos delitos producen menoscabo al erario público que, en muchas ocasiones, repercute en el adecuado funcionamiento del gobierno. Se entiende entonces que la reparación al patrimonio del Estado es igual de importante que a las víctimas particulares.

Ahora bien, para entender la importancia del tema de recuperación de activos es necesario identificar las principales formas delictivas que originan los daños al patrimonio del Estado. En el caso de México, la problemática va entorno a dos fenómenos complejos y de gran magnitud: corrupción y delincuencia organizada. Ambos se han posicionado en la agenda política y mediática del país

\footnotetext{
${ }^{3}$ Asamblea General de las Naciones Unidas, "40/34 Declaración sobre los principios fundamentales de justicia para las víctimas de delitos y del abuso de poder", 1985, [En línea] http://www.ohchr.org/SP/Professionallnterest/Pages/VictimsOfCrimeAndAbuseOfPower.aspx
} 
en las últimas décadas. A continuación se incluyen algunos datos e ideas al respecto:

1) Es cada día más evidente la evolución del problema de corrupción en México. En el plano internacional, Transparencia Internacional ha documentado en el Índice de Percepción de la Corrupción $2017^{4}$ el descenso de 30 posiciones en el ranking mundial, cayendo hasta el lugar 135 de 180 territorios evaluados, en un periodo de cinco años. Si bien el estudio mide percepción en la ciudadanía, es innegable el reflejo de la creciente problemática en el país.

2) La fragilidad de las instituciones del gobierno mexicano fue evidenciada en el caso "Odebrecht". Se estima que entre el 2001 y 2016 el país recibió 10.5 millones de dólares producto del cohecho a cambio de la asignación de diversas obras por parte del gobierno federal a la constructora brasileña. Si bien la investigación sigue abierta, no existen a la fecha resultados que favorezcan la percepción sobre la procuración e impartición de justicia en el caso.

3) La delincuencia organizada es un mal que sigue ocupando la agenda en el país. La estrategia de combate a este tipo de delincuencia lleva ya diez años en el mismo sentido y no ha generado resultados favorables importantes. En cambio, una ola de violencia sacude al país y crea un ambiente de inseguridad e impunidad que no abona al reclamo social por mejores condiciones de vida y el restablecimiento de la paz.

\footnotetext{
4 Índice de percepción de la corrupción, Transparencia Internacional, [En línea] consultado el 14 de octubre de 2018 en: https://www.transparency.org/research/cpi/overview
} 
Corroborando lo anteriormente señalado se tiene la Encuesta Nacional de Calidad e Impacto Gubernamental (ENCIG), ${ }^{5}$ que a 2017 registra como el principal problema a nivel nacional la inseguridad y delincuencia, mismo que persiste en las cuatro ediciones bienales de este estudio. Esto evidencia la magnitud de la problemática en el país, aunado a las cifras de muertos y desaparecidos producto de la guerra contra el narco, que siguen en aumento. ${ }^{6}$

Por otro lado, es importante también considerar el poderío del crimen organizado en términos económicos: "detrás de las cifras sangrientas existe un negocio que significa un valor de 40,000 millones de dólares por año para las organizaciones criminales mexicanas y sus afiliadas" ${ }^{7}$. Ignorar este elemento significa atacar al problema parcialmente, dejando una fuente de subsistencia para las organizaciones criminales.

Ante la complejidad de las nuevas formas delictivas, el derecho penal debe considerar, entre otras cosas: a) las facilidades en materia de telecomunicaciones; b) los intercambios comerciales internacionales; c) la apertura de fronteras; d) la flexibilización de las formalidades al tránsito por diferentes países, como

\footnotetext{
${ }^{5}$ Instituto Nacional de Estadística y Geografía (INEGI), "Encuesta Nacional de Calidad e Impacto Gubernamental" [En línea] consultado el 14 de octubre de 2018 en: http://www.beta.inegi.org.mx/proyectos/enchogares/regulares/encig/2017/default.html

${ }^{6}$ Conservadoramente, se estiman 100 mil víctimas de la llamada guerra contra el narco, aunque algunas publicaciones manejan cifras de $150 \mathrm{mil}$, además de 30 mil personas desaparecidas. Evidentemente se está ante una estructura poderosa y difícil de combatir que ha logrado empoderarse y controlar territorios en todos los estados. Las cifras manejadas por medios de comunicación oscilan entre estos rangos, aunque no se puede tener con exactitud un número exacto de víctimas.

Fuentes: Milenio (Agencia) "A 10 años de la guerra contra el narco: 100 mil muertos y 30 mil desaparecidos" [En línea] consultado el 09 de septiembre de 2018 en: http://www.milenio.com/policia/10-anos-guerra-narco-100-mil-muertos-30-mildesaparecidos; y Pardo, José Luis, "México cumple una década de duelo por el fracaso de la Guerra contra el Narco", New York Times [En línea] consultado el 09 de septiembre de 2018 en: https://www.nytimes.com/es/2016/09/07/mexico-cumple-una-decada-deduelo-por-el-fracaso-de-la-guerra-contra-el-narco/

7 Camarena, Jorge, "La economía detrás del narcotráfico", El Economista, [En línea] consultado el 09 de septiembre de 2018 en:

https://www.eleconomista.com.mx/politica/La-economia-detras-del-narcotrafico-

20130108-0178.html
} 
elementos provechosos para el delincuente moderno. ${ }^{8}$ En otras palabras, debe tomar en cuenta que las nuevas formas delictivas se han adaptado cómodamente a los avances tecnológicos y sociales de la era.

Con relación a lo señalado en el párrafo que precede, se vuelve indispensable y necesario reflexionar sobre los mecanismos con que cuenta el derecho penal para el logro de sus objetivos. Consecuencia de la internacionalización de la criminalidad contemporánea ${ }^{9}$, la recuperación de activos se posiciona en la agenda global como una etapa insustituible en su combate. Las medidas para lograrlo, dado el carácter de esta delincuencia, se diseñan igualmente en un plano internacional. ${ }^{10}$

De la obra Nieto y Maroto $^{11}$ se sintetizan en tres consideraciones sobre la complejidad que conlleva en su ejecución la recuperación de activos:

1) Los costes económicos de localización de bienes, honorarios de abogados, así como el empleo de técnicas de investigación, son muy elevados y pueden representar una limitante para la recuperación de activos; los costes personales que puede representar el combate a la corrupción en regímenes dictatoriales pueden suponer un riesgo a la vida;

2) La ausencia de voluntad política pareciera un obstáculo insalvable en algunos Estados;

\footnotetext{
${ }^{8}$ Núñez, Miguel, "Mercado internacional y corrupción”, en Ferré, Juan (coord.), Korupcjia w sektorze prywatnym, Wydawnictwo Naukowe, Varsovia, 2004, pp. 11

${ }^{9}$ Núñez, Miguel, "Mercado internacional y corrupción", en Ferré, Juan (coord.), Korupcjia w sektorze prywatnym, Wydawnictwo Naukowe, Varsovia, 2004, p. 12.

${ }^{10}$ Moreno, Moisés, "Política criminal frente a la delincuencia organizada en México", en García, Sergio y Vargas, Leticia (coords.), Las reformas penales en los últimos años en México (1995-2000), IIJ-UNAM, México, 2001, p. 157 [En línea] consultado en el 09 de septiembre de 2018 en:

https://biblio.juridicas.unam.mx/bjv/detalle-libro/131-las-reformas-penales-de-los-ultimosanos-en-mexico-1995-2000

11 Nieto, Adán y Maroto, Manuel (directores), Public compliance. Prevención de la corrupción en administraciones públicas y partidos políticos. Ediciones de la Universidad de Castilla-La Mancha, Cuenca, 2014, p. 280.
} 
3) El "dilema de la devolución", es decir, la idea de si merece la pena el esfuerzo de devolver activos en favor de un país que no ofrece la seguridad del buen uso de los activos recuperados.

Por otro lado, es importante considerar que el hablar de recuperación del producto del delito es hablar de derechos humanos, en dos sentidos: 1) posibilita la reparación a las víctimas particulares como parte de sus derechos en el procedimiento penal y 2) contribuye al saneamiento del erario público y con ello, indirectamente, se contribuye a la protección de derechos humanos, en especial, aquellos de segunda generación. ${ }^{12}$

Es substancial ver en la afectación al patrimonio del Estado un área de vulnerabilidad de derechos humanos. Es reconocido que la repatriación de fondos de origen ilícito constituye un importante elemento en la movilización de recursos para el desarrollo de los países. ${ }^{13}$ Con la merma al presupuesto público se reducen o afectan programas sociales y políticas públicas, atenuando muchas veces los beneficios que éstos pueden brindar para el desarrollo de grupos sociales vulnerables.

En las siguientes páginas se hace una recopilación de la normativa internacional que contempla la figura de la recuperación de activos y la cooperación judicial con este fin; asimismo, la normativa nacional que plasma diferentes figuras jurídicas que permiten la recuperación de activos y la aplicación que éstas pueden tener en el combate a la corrupción, especialmente.

\footnotetext{
${ }^{12}$ La corrupción y los derechos humanos. Estableciendo el vínculo. Consejo Internacional para el Estudio de los Derechos Humanos (CIEDH), 2009, pp. 8-13 [En línea] consultado el 09 de septiembre de 2018 en:

http://workspace.unpan.org/sites/Internet/Documents/UNPAN041206.pdf

13 Asamblea General de las Naciones Unidas, Resolución 56/186. "Prevención de las prácticas corruptas y la transferencia de fondos de origen ilícito y lucha contra ellas y repatriación de esos fondos a sus países de origen", 2002, [En línea] consultado el 09 de septiembre de 2018 en:

http://www.un.org/es/comun/docs/?symbol=A/RES/56/186
} 


\section{Normatividad internacional}

La figura de recuperación de activos está contenida en diversos instrumentos internacionales, cuyos orígenes datan los años alrededor del inicio de este siglo. Fundamentalmente, entre los instrumentos aplicables en México se tienen los siguientes:

1. Convención Interamericana Contra la Corrupción (1996);

2. Convención para Combatir el Cohecho de Servidores Públicos Extranjeros en Transacciones Comerciales Internacionales (1997);

3. Convención de las Naciones Unidas contra la Delincuencia Organizada Trasnacional (2000);

4. Convención de las Naciones Unidas contra la Corrupción (2003).

Para su mejor abordaje, se desarrollan a continuación los principales aspectos relacionados a la recuperación de activos que contempla cada instrumento:

1) Convención Interamericana Contra la Corrupción. ${ }^{14}$

Se erige como uno de los primeros instrumentos internacionales para el combate a la corrupción. Esta convención fue suscrita en 1996 en la ciudad de Caracas, Venezuela, por la mayoría de los países que conforman la Organización de Estados Americanos (OEA). Dicha Convención tiene como propósitos:

1. Promover y fortalecer el desarrollo, por cada uno de los Estados Partes, de los mecanismos necesarios para prevenir, detectar, sancionar y erradicar la corrupción;

2. Promover, facilitar y regular la cooperación entre los Estados Partes a fin de asegurar la eficacia de las medidas y acciones para prevenir, detectar, sancionar y erradicar los actos de corrupción en el ejercicio de las funciones públicas y los actos de corrupción específicamente vinculados con tal ejercicio.

\footnotetext{
14 Organización de los Estados Americanos (OEA), "Convención Interamericana contra la Corrupción", 1996 [En línea] consultado el 09 de septiembre de 2018 en: http://www.oas.org/es/sla/ddi/tratados_multilaterales_interamericanos_B58_contra_Corrupcion.asp
} 
Por lo que toca a esta normativa, se puede considerar laxa en el tema de recuperación de activos, pues únicamente dispone en su artículo XV el compromiso de los Estados Partes de prestarse mutua asistencia para la identificación rastreo, inmovilización confiscación y decomiso de bienes derivados de la comisión de delitos tipificados en la misma Convención. Asimismo, establece que los Estados Partes dispondrán de los bienes o productos sobre los que apliquen sentencias, propias o externas, relativas a la figura del decomiso. En la medida que su marco legal lo permita, podrán transferir total o parcialmente los bienes en cuestión.

\section{2) Convención para Combatir el Cohecho de Servidores Públicos} Extranjeros en Transacciones Comerciales Internacionales. ${ }^{15}$

Fue pactada en el marco de la Organización para la Cooperación y el Desarrollo Económicos (OCDE) en 1997 y es un precedente en la recuperación de activos, ya que dispone que los Estados parte tomarán medidas para que el producto del cohecho de servidores públicos esté sujeto a incautación y decomiso.

Si bien, la Convención sólo toca este punto en el artículo tercero, da origen a la Recomendación del Consejo para Fortalecer la Lucha Contra el Cohecho de Servidores Públicos Extranjeros en Transacciones Comerciales Internacionales, donde se amplían las disposiciones para la recuperación de activos.

Dicha recomendación plantea que los países miembros cooperarán con otros países en investigaciones y diligencias jurídicas respecto a casos de cohecho trasnacional, compartiendo información, suministrando pruebas, mediante la extradición, así como en la identificación, embargo preventivo, incautación, decomiso y recuperación del producto de este delito.

\footnotetext{
${ }^{15}$ Organización para la Cooperación y el Desarrollo Económicos (OCDE), "Convención para combatir el cohecho de servidores públicos extranjeros en transacciones comerciales internacionales y Documentos relacionados", 1997 [En línea] consultado el 09 de septiembre de 2018 en: https://www.oecd.org/daf/antibribery/ConvCombatBribery_Spanish.pdf
} 
3) Convención de las Naciones Unidas contra la Delincuencia Organizada Trasnacional. ${ }^{16}$

Esta convención surge de la preocupación de los países miembros de la Organización de las Naciones Unidas por las repercusiones económicas y sociales que ocasiona la actividad delictiva organizada, a fin de crear y fortalecer la cooperación internacional para su prevención y combate eficaz en el plano trasnacional.

En dicho instrumento se establece el compromiso de los Estados Parte por adoptar medidas en sus ordenamientos jurídicos que permitan el decomiso de los productos del delito, entendiendo éstos como los "bienes de cualquier índole derivados u obtenidos directa o indirectamente de la comisión de un delito". Cabe aclarar que este compromiso hace referencia a los bienes producto de delitos graves ${ }^{17}$. Además, la convención establece que los Estados Parte podrán considerar la posibilidad de exigir a un delincuente que demuestre el origen lícito del presunto producto del delito o de otros bienes expuestos al decomiso, de conformidad con los principios del derecho interno.

\section{4) Convención de las Naciones Unidas contra la Corrupción. ${ }^{18}$}

La llamada "Convención de Mérida" surge entendiendo a la corrupción como un "fenómeno trasnacional que afecta a todas las sociedades y economías". Este instrumento establece entre sus finalidades la cooperación internacional y asistencia técnica en materia de prevención y lucha contra la corrupción, incluida la recuperación de activos.

\footnotetext{
${ }^{16}$ Naciones Unidas - Oficina contra la Droga y el Delito, "Convención de las Naciones Unidas contra la Delincuencia Organizada Trasnacional y sus protocolos", 2004 [En línea] consultado el 09 de septiembre de 2018 en: https://www.unodc.org/documents/treaties/UNTOC/Publications/TOC \%20Convention/TOC ebook-s.pdf

${ }^{17}$ En términos del artículo 2, inciso b) de la Convención, se entiende por delito grave: "la conducta que constituya un delito punible con una privación de libertad máxima de al menos cuatro años o con una pena más grave".

18 Naciones Unidas-Oficina contra la Droga y el Delito, "Convención de las Naciones Unidas contra la Corrupción", 2003 [En línea] consultado el 09 de septiembre de 2018 en: https://www.unodc.org/pdf/corruption/publications_unodc_convention-s.pdf
} 
Igualmente, esta convención refleja de forma más concreta la intención de los Estados Parte por realizar acciones que ayuden a prevenir, detectar y disuadir las transferencias internacionales de activos ilícitos, así como fortalecer la cooperación para su recuperación en el plano internacional. En su ámbito de aplicación refiere al embargo preventivo, la incautación, el decomiso y la restitución del producto del delito.

Contempla también el compromiso de los Estados Parte por establecer la responsabilidad a las personas jurídicas que participen en los delitos considerados en la misma convención, concluyendo en sanciones eficaces, proporcionadas y disuasivas de los tipos penales considerados de corrupción ${ }^{19}$.

En este instrumento se plantea también que cada Estado Parte autorice medidas para el decomiso del producto de delitos o bienes con valor equivalente y de bienes, equipo u otros instrumentos utilizados en la comisión del delito, o destinados a la comisión del mismo. Asimismo, deberán adoptar las medidas para regular la administración de los bienes embargados, incautados o decomisados.

En cuanto a las instituciones financieras, establece que cada Estado Parte adoptará las medidas necesarias en su derecho interno para que aquellas que funcionan en su territorio cumplan con los requisitos siguientes:

- Verifiquen la identidad de sus clientes;

- Adopten medidas razonables para determinar beneficiarios finales de fondos depositados en cuentas de valor elevado;

- Intensifiquen el escrutinio de toda cuenta solicitada o mantenida por o a nombre de personas que desempeñen o hayan desempeñado funciones prominentes y de sus familiares y estrechos colaboradores.

\footnotetext{
${ }^{19}$ La Convención de las Naciones Unidas contra la Corrupción en su capítulo III señala como delitos objeto de la misma a los siguientes: soborno de funcionarios públicos nacionales, funcionarios públicos extranjeros y de funcionarios de organizaciones internacionales públicas, peculado, tráfico de influencias, abuso de funciones, enriquecimiento ilícito, soborno en el sector privado, peculado en el sector privado, blanqueo del producto del delito, encubrimiento y obstrucción de la justicia.
} 
De igual manera, plantea que cada Estado Parte, con arreglo a su derecho interno, deberá realizar adecuaciones afines a entablar cooperación internacional con fines de decomiso, por lo que -cuando menos- deberá:

- Impartir directrices sobre el tipo de personas, naturales o jurídicas, cuyas cuentas bancarias deban someterse a mayor escrutinio, así como las transacciones a las que deba prestarse particular atención;

- Notificar a las instituciones financieras la identidad de determinadas personas a las que deberá someter a mayor escrutinio, por iniciativa propia o a solicitud de otro Estado Parte;

- Mantener registros de cuentas y transacciones que permitan identificar datos básicos del cliente y beneficiario final, en aquellas personas sujetas a mayor escrutinio;

- Aplicar medidas para impedir el establecimiento de bancos sin presencia real o que no estén afiliados a un grupo financiero sujeto a regulación, así como impedir que otras instituciones financieras establezcan relaciones con éstos;

- Establecer sistemas de divulgación de información financiera para servidores públicos pertinentes, así como sanciones adecuadas para todo incumplimiento del deber de declarar;

- Exigir a los servidores públicos que tengan algún derecho o poder de firma o de otra índole en alguna cuenta financiera de país extranjero, que declaren su relación con esa cuenta a las autoridades competentes y lleven el debido registro.

Sumando a lo que antecede, también se pacta en el artículo 53 de la convención que cada Estado Parte adoptará medidas para facultar a otros Estados para entablar acciones por la vía civil, a fin de determinar la propiedad de bienes adquiridos mediante delitos tipificados en la convención, para que quienes hayan cometido estos delitos indemnicen o resarzan por daños y perjuicios a otro Estado Parte.

Por otro lado, señala que se adoptarán las medidas para que las autoridades competentes reconozcan el legítimo derecho de propiedad de otro Estado Parte sobre los bienes adquiridos mediante la comisión de un delito, en decisiones relacionadas al decomiso del producto del delito.

En cuanto a cooperación judicial, los Estados Parte se comprometen a adoptar medidas para que sus autoridades puedan: 
- Dar efecto a toda orden de decomiso dictada por un tribunal de otro Estado Parte;

- Ordenar el decomiso de bienes de origen extranjero en una sentencia relativa a los delitos sobre los que puedan tener jurisdicción;

- Permitir el decomiso de bienes producto del delito cuando el delincuente no pueda ser enjuiciado por causa sobreviniente;

- Efectuar el embargo preventivo de bienes en cumplimiento de una solicitud de otro Estado Parte, cuando constituya un fundamento razonable para ello.

En cuanto a la asistencia judicial recíproca, las solicitudes que expresen los Estados Parte pueden ir en tres sentidos:

1) Solicitar el decomiso de bienes fuera de su territorio, en cuyo caso deberán realizar una descripción de los bienes susceptibles de decomiso y, en lo posible, la ubicación, el valor estimado y una exposición de hechos en los que basa la solicitud;

2) Solicitar la ejecución en el territorio del Estado Parte requerido, de una orden de decomiso decretada en su interior, para lo cual deberán proporcionar una copia admisible en derecho de la orden de decomiso expedida, una exposición de hechos y la información que proceda sobre el grado de ejecución que se solicita, una declaración en el que se indiquen las medidas adoptadas para dar notificación adecuada a terceros de buena fe y para garantizar el debido proceso, y un certificado de que la orden de decomiso es definitiva.

3) Solicitar el embargo preventivo o incautación, en miras de su eventual decomiso, para lo cual deberán proporcionar una exposición de hechos que basan la solicitud, una descripción de las medidas solicitadas y, cuando se disponga de ella, una copia admisible en derecho de la orden de decomiso en cuestión.

\section{Marco jurídico mexicano}

1. Decomiso 
Es una figura jurídica producto de una sanción por la comisión de un delito, consistente en la pérdida de los instrumentos, objetos y productos del delito. Su fundamento jurídico viene del segundo párrafo del artículo 22 de la Constitución General, donde se especifican los casos en que es permisible la confiscación de bienes como pena.

Más específicamente esta figura aparece en el Código Penal Federal, que en su artículo 24 señala como pena aplicable al delito el decomiso, así como expresamente menciona el decomiso de bienes correspondientes del enriquecimiento ilícito. Este artículo señala como excepción a los bienes que hayan causado abandono o sobre los cuales se haya declarado extinción de dominio.

Derivado de lo señalado en el anterior existen criterios de la Suprema Corte ${ }^{20}$ en los que detalla que el decomiso se reduce a los bienes que guardan una relación con la conducta que se castiga, es decir, los que han sido utilizados como instrumento para la comisión de un delito o infracción administrativa, los que han resultado como fruto de ilícitos o los que por sus características representan un peligro para la sociedad.

En su primera versión, de 1931, el Código Penal Federal señalaba que estos instrumentos decomisados por su relación con la conducta delictiva serían destruidos si sólo sirvieren para delinquir; a excepción de ese caso, se aplicarían al Estado si fueren útiles o se venderían a personas que no tengan prohibido usarlos y su precio serviría para la mejora material de las prisiones. ${ }^{21}$

En 1945 fue publicado el decreto que reformaba el artículo 40 del código en comento, sobre decomiso de bienes. Considerando la escasez de materiales por la guerra, se contemplaba que los bienes a disposición de la autoridad judicial, cuyos dueños no los hubieren reclamado en un plazo de tres años, pasaban a ser

${ }^{20}$ Tesis: P. LXXIV/96, Semanario Judicial de la Federación y su Gaceta, Novena Época, t. III, mayo de 1996, p. 55.

${ }^{21}$ Arts. 40 y 41 del Código Penal para el Distrito y Territorios Federales en Materia de Fuero Común, y para toda la República en materia de Fuero Federal, 2 de enero de 1931 http://www.diputados.gob.mx/LeyesBiblio/ref/cpf/CPF_orig_14ago31_ima.pdf 
considerados bienes mostrencos y se procedería a su venta, en aras de un mejor aprovechamiento. ${ }^{22}$

En 1951 se reformó nuevamente este artículo y el subsecuente, retomando los supuestos del artículo de 1931: 1) que los instrumentos u objetos sean de uso prohibido y 2) que el acusado fuere condenado por delito intencional; para terceras personas el decomiso habría de proceder cuando los instrumentos hayan sido utilizados con fines delictuosos y con conocimiento del propietario. ${ }^{23}$

Por otra parte, un cambio notable tiene que ver con el destino de los bienes decomisados. En 1974 se empezó a disponer de los bienes según su especie, destinando el dinero o valores a la Secretaría de Hacienda y Crédito Público, mientras que los objetos se remitirían a la entonces existente Secretaría del Patrimonio, para su aprovechamiento en favor del Estado. ${ }^{24}$

En 1983 se agrega al artículo 24 el inciso 18, con lo cual se considera como sanción el decomiso de bienes correspondientes al enriquecimiento ilícito, aunado a una serie de reformas a los tipos penales de los delitos cometidos por servidores públicos, entre los cuales se contempla el Enriquecimiento ilícito y la pena de decomiso de los bienes cuya legal procedencia no se acredite. ${ }^{25}$

Actualmente la figura del decomiso sigue vigente en el Código Penal Federal, conservando algunas características a lo largo del tiempo. Además, hoy día la desaparición de los bienes por causa atribuible al imputado o sentenciado

\footnotetext{
${ }^{22}$ Diario Oficial de la Federación, martes 8 de mayo de 1945, Tomo CL, No. 5, consultado el 14 de octubre de 2018 en:

http://www.diputados.gob.mx/LeyesBiblio/ref/cpf/CPF_ref09_08may45_ima.pdf

${ }^{23}$ Diario Oficial de la Federación, lunes 15 de enero de $\overline{1951, ~ T o m o ~ C L X X X I V, ~ N o . ~} 12$, consultado el 14 de octubre de 2018 en:

http://www.diputados.gob.mx/LeyesBiblio/ref/cpf/CPF_ref17_15ene51_ima.pdf

${ }^{24}$ Diario Oficial de la Federación, Martes 31 de diciembre $\overline{\text { de }} 1974$, consultado el 14 de octubre de 2018 en:

http://www.diputados.gob.mx/LeyesBiblio/ref/cpf/CPF_ref34_31dic74_ima.pdf

${ }^{25}$ Diario Oficial de la Federación, miércoles 5 de eñero de 1983 , consultado el 14 de octubre de 2018 en:

http://www.diputados.gob.mx/LeyesBiblio/ref/cpf/CPF_ref45_05ene83_ima.pdf
} 
da pie al decomiso de otros bienes en su propiedad o sobre los que se conduzcan como dueños, con un valor equivalente al producto del delito.

Aunado a lo anterior, en la legislación adjetiva el decomiso se considera en el Código Nacional de Procedimientos Penales como una sanción que podrá ser decretada por autoridad judicial mediante sentencia, sobre los bienes relativos al delito a excepción de los que causen abandono o sobre los que se resuelva declaratoria de extinción de dominio.

Al respecto es importante destacar que esta nueva codificación expresamente establece que una vez satisfecha la reparación a la víctima habrá el Estado de disponer de los bienes decomisados y ponerlos a disposición del Poder Judicial, la Procuraduría General de la República, Secretaría de Salud y el Fondo de ayuda, asistencia y reparación integral, derivado de la Ley General de Víctimas.

\section{Abandono}

La figura del abandono de bienes también es contemplada en el Código Penal Federal, como consecuencia de que los bienes en posesión de las autoridades investigadoras o judiciales que no hayan sido decomisados, no sean recogidos por quienes tienen derecho a ello. Entonces, se dispone sean enajenados en subasta pública y su venta sea aplicada al mejoramiento de la administración de justicia. En este sentido, se precisa que en aquellos casos en que los bienes no se deban destruir y no se puedan conservar o su mantenimiento sea costoso, se debe proceder a su venta inmediata y el producto de dicho acto se dejará a disposición de quien tenga derecho a reclamar los bienes, por un plazo de seis meses a partir de que se le notifique.

En esencia la figura del abandono de bienes se ha mantenido a través del tiempo en el Código Penal sin mayor variación que los plazos que la autoridad deberá atender para la custodia de los bienes. Por ejemplo, en $1951^{26}$ se reformó el artículo 41 del citado código, quedando establecido el plazo de tres años a partir

${ }^{26}$ Op. cit. nota 21. 
de que proceda su devolución para que empiecen a considerarse bienes mostrencos.

En 1965 se consideró también aquellos objetos que se encontraran en poder de las autoridades investigadoras. Se dispuso que el producto recabado por autoridades federales en este procedimiento se destinaría al mejoramiento de las instituciones dedicadas al tratamiento de menores infractores de las leyes penales. ${ }^{27}$ Esta disposición desaparece en 1974 y se remplaza por "su mejor aprovechamiento o su venta". ${ }^{28}$

De 1984 a la fecha, el plazo para reclamar los bienes establecido en el Código Penal se redujo de seis meses a 90 días naturales por lo que, de no ser reclamados por quien tenga derecho a ello, causarán estado de abandono y se procederá en los términos anteriormente expuestos para su aprovechamiento en favor del Estado.

Es importante destacar que el Código Nacional de Procedimientos Penales contempla un procedimiento para la declaratoria de abandono de bienes producto del delito. En el artículo 231 de dicho ordenamiento se establecen las formalidades que deberán atender Ministerio Público y Juez de control para poder realizar la declaratoria en cuestión.

Así, el Ministerio Público deberá notificar al interesado sobre el aseguramiento del bien, dentro de los 60 días posteriores, permitiendo que el interesado manifieste lo que a su derecho convenga. En la notificación se le concederá un plazo de 90 días para manifestarse o da lugar a que el Ministerio Público solicite al Juez de control la declaración de abandono, a favor de la Procuraduría federal o su homóloga local.

El Juez de control dará curso a la solicitud haciendo citación a audiencia al Ministerio público, a la víctima u ofendido y al interesado, verificando que la

\footnotetext{
${ }^{27}$ Diario Oficial de la Federación, miércoles 13 de enero de 1965, Tomo CCLXVIII, No. 10, consultado el 14 de octubre de 2018 en:

http://www.diputados.gob.mx/LeyesBiblio/ref/cpf/CPF_ref21_13ene65_ima.pdf

${ }^{28}$ Op. cit. nota 22.
} 
notificación al interesado cumpla con las formalidades procesales y que los plazos respectivos ya hayan concluido. Una vez declarado el abandono se notificará a la autoridad que los custodie, para proceder a enajenar y liquidarlos, para efecto de que sean destinados a la Procuraduría.

En este procedimiento y en los casos de decomiso es importante considerar la Ley Federal para la Administración y Enajenación de Bienes del Sector Público, que establece las atribuciones del Servicio de Administración y Enajenación de Bienes (SAE), sobre la administración de bienes y enajenación de los mismos a partir de que le son conferidos a la SAE.

Así, las Autoridades judiciales federales y la misma Procuraduría podrán remitir los bienes en cuestión al $\mathrm{SAE}^{29}$, para que proceda a venderlos a través de los procedimientos siguientes: 1) licitación pública, 2) subasta (medio preferente ${ }^{30}$ ), 3) remate y 4 ) adjudicación directa. Una vez realizada la venta, el monto obtenido una vez deducidos los gastos será destinado a la Procuraduría.

3. Extinción de dominio

La extinción de dominio es la pérdida de los derechos sobre los bienes (entendiéndose como todas las cosas materiales que no estén excluidas del comercio, muebles o inmuebles, así como derechos reales o personales, objetos, frutos y productos susceptibles de apropiación) relacionados o vinculados a determinados delitos, sin contraprestación ni compensación alguna para su dueño ni para quien se ostente o comporte como tal. ${ }^{31}$

\footnotetext{
${ }^{29}$ En el artículo $1^{\circ}$ de la Ley Federal para la Administración y Enajenación de Bienes del Sector Público (LFAEBSP) se enlistan aquellos bienes susceptibles de ser transferidos al SAE para su administración y enajenación. Entre sus fracciones se señalan aquellos bienes que hayan sido decomisados o asegurados en procedimientos penales federales y aquellos que hayan sido abandonados en favor del gobierno federal.

Consultado el 14 de octubre de 2018 en:

http://www.diputados.gob.mx/LeyesBiblio/pdf/251.pdf

30 Artículo 39 de la LFAEBSP.- La venta de los bienes se realizará preferentemente a través del procedimiento de subasta.

${ }^{31}$ Artículos 2 fr. I, 3 y 8, todos de la Ley Federal de Extinción de Dominio.
} 
Esta figura tiene su origen en el artículo 22 de la Constitución General, como uno de los supuestos que se excluyen de la confiscación (prohibida en el primer párrafo de dicho artículo). Fue añadida en la reforma del 8 de junio de $2008^{32}$ y considera los siguientes aspectos fundamentales que habrán de atenderse para declarar la extinción de dominio:

1) se declarará previo a un procedimiento jurisdiccional y autónomo del procedimiento en materia penal ${ }^{33}$;

2) procede sólo en casos de delincuencia organizada, delitos contra la salud, secuestro, robo de vehículos, trata de personas y enriquecimiento ilícito $^{34}$, sobre determinados bienes ${ }^{35}$.

${ }^{32}$ Diario Oficial de la Federación, miércoles 18 de junio de 2008, Primera sección, consultado el 14 de octubre de 2018 en:

http://www.diputados.gob.mx/LeyesBiblio/ref/dof/CPEUM_ref_180_18jun08_ima.pdf

33 Al respecto, la Suprema Corte de Justicia de la Nación ha determinado que tal autonomía es relativa y no absoluta, pues debe entenderse la separación entre los órganos jurisdiccionales del procedimiento penal y del de extinción de dominio considerando la independencia en tres aspectos:

"a) en la normatividad que cada uno de ellos ha de aplicar en el proceso del que es rector;

b) en el desarrollo de cada uno de los juicios ;

c) en la decisión que adopten sobre temas respecto de los cuales no compartan jurisdicción (básicamente la responsabilidad penal, por no ser éste un tópico sobre el que ambos jueces deban decidir)."

Además, habrá de considerarse que ambos procedimientos mantienen su relación en que se originan por los hechos que dieron origen a la averiguación previa, estando el penal encaminado a la sanción por la comisión de delitos y el de extinción de dominio a la declaración de derechos patrimoniales.

Tesis: 1a./J. 21/2015 (10a.), Semanario Judicial de la Federación y su Gaceta, Décima Época, t. I, abril de 2015, p. 340.

${ }^{34}$ Este tipo penal se añadió al listado con posterioridad, en una reforma publicada el 27 de mayo de 2015 en la que se incluyen una serie de modificaciones a la constitución en materia de combate a la corrupción, entre las que destaca la creación del Sistema Nacional Anticorrupción.

Diario Oficial de la Federación, miércoles 27 de mayo de 2015, consultado el 14 de octubre de 2018 en:

http://www.diputados.gob.mx/LeyesBiblio/ref/dof/CPEUM_ref_223_27may15.pdf

${ }^{35}$ Artículo 22, párrafo 2, fracción II:

“a) Aquellos que sean instrumento, objeto o producto del delito, aún cuando no se haya dictado la sentencia que determine la responsabilidad penal, pero existan elementos suficientes para determinar que el hecho ilícito sucedió. 
Con posterioridad a la reforma constitucional mencionada se publicó la Ley Federal de Extinción de Dominio (LFED), en Mayo de 2009. En este ordenamiento se establecen las bases de este procedimiento, quedando reglamentadas las disposiciones del artículo 22 constitucional.

Así, en la LFED se define a la extinción de dominio como una acción de carácter real que corresponde al Ministerio Público y de la cual deberán conocer jueces especializados que para tal efecto establezca el Poder Judicial de la Federación. Para que se configure la prescripción de esta acción atiende las mismas reglas que para la prescripción de los delitos precedentes sobre los cuales puede proceder.

Las partes de este procedimiento son: 1) el Ministerio Público, fungiendo como actor; 2) quien se ostente como dueño o titular de los derechos, quien será demandado; y 3) quienes se consideren afectados y acrediten un interés jurídico. Se sigue, supletoriamente a esta ley, las disposiciones aplicables al procedimiento civil federal.

Como resultado de este procedimiento se pueden tener dos resultados: 1) la declaración de improcedencia de la acción; y 2) la declaración de extinción de dominio, haciéndose la debida separación de cada bien objeto del procedimiento. Para efecto de determinar la procedencia de la extinción de dominio, el Juez habrá de considerar que el Ministerio Público acredite lo siguiente:

a) plenamente los elementos del cuerpo del delito precedente;

b) que los bienes caen en los supuestos de la fracción II del artículo 22 constitucional, es decir, que sean instrumento, objeto o producto del delito, que

b) Aquellos que no sean instrumento, objeto o producto del delito, pero que hayan sido utilizados o destinados a ocultar o mezclar bienes producto del delito, siempre y cuando se reúnan los extremos del inciso anterior.

c) Aquellos que estén siendo utilizados para la comisión de delitos por un tercero, si su dueño tuvo conocimiento de ello y no lo notificó a la autoridad o hizo algo para impedirlo.

d) Aquellos que estén intitulados a nombre de terceros, pero existan suficientes elementos para determinar que son producto de delitos patrimoniales o de delincuencia organizada, y el acusado por estos delitos se comporte como dueño." 
hayan sido utilizados o destinados para ocultar o mezclar bienes producto del delito;

c) que los bienes hayan sido utilizados por terceros para la comisión de delitos, con conocimiento del propietario y donde se pruebe plenamente la actuación de mala fe del tercero; y

d) aquellos intitulados a nombre de terceros y se acredite que son producto de la comisión de delitos, cuando se pruebe la procedencia ilícita de los bienes.

Cuando cause ejecutoria la sentencia y se resuelva sobre la extinción del dominio sobre determinado bien se ordenará su ejecución y aplicación de bienes a favor del Estado, atendiendo lo dispuesto en el artículo 54 de la LFED, que marca el orden de prelación siguiente:

“I. Reparación del daño causado a la víctima u ofendido de los delitos, cuando los hubiere por los que se siguió la acción de extinción de dominio, determinada en la sentencia ejecutoriada del proceso correspondiente; o bien en los casos a que se refiere el párrafo cuarto de este artículo, en los que el interesado presente la resolución favorable del incidente respectivo, y

II. Las reclamaciones procedentes por créditos garantizados."

\section{Aplicación en el combate a la corrupción}

Como anteriormente se mencionó, la reparación del daño es un componente esencial si se quiere aproximar al ideal de justicia. Es por ello que se vuelve fundamental la aplicación de mecanismos que posibiliten la recuperación de activos, para poder subsanar las afectaciones patrimoniales que pudieran sufrir las víctimas u ofendidos del delito. En este orden de ideas, cuando el delito en cuestión se vincula al fenómeno de la corrupción es evidente la necesidad de cubrir el vacío económico que genera en el erario público el desvío de recursos en sus diferentes modalidades, así como el decomisar la riqueza generada por motivo del aprovechamiento indebido del poder público.

Ante la realidad del país en materia de corrupción, la recuperación de activos es una de las principales demandas de una sociedad que exige justicia frente a una innegable afectación económica al país derivada de este fenómeno. 
Si bien no se tienen cifras oficiales sobre el costo total de este problema por la dificultad de estimarlas, es perceptible que la magnitud del problema es amplia.

Al respecto, la Red por la Rendición de Cuentas (RRC) y el Centro de Investigación y Docencia Económicas (CIDE) mencionan en su documento preliminar sobre la política nacional anticorrupción que el decomiso del producto y de los instrumentos del delito "no se persigue en forma sistemática como un objetivo de las políticas y no es proporcional con los riesgos de lavado de activos y financiamiento al terrorismo". ${ }^{36}$

Sobre ello, el Grupo de Acción Financiera (GAFI) y el Grupo de Acción Financiera de Latinoamérica (GAFILAT) presentan en su Informe de Evaluación Mutua de 2018, sobre medidas anti lavado y contra la financiación del terrorismo, el nivel de cumplimiento que tiene México a las recomendaciones que emiten, entre muchas más, sobre el decomiso de bienes y medidas provisionales para prevenir este tipo de actividad ilícita.

$\mathrm{Si}$ bien, su enfoque no es hacia el combate a la corrupción, refleja resultados interesantes en el avance del país para implementar estas medidas, así como áreas de oportunidad. Señala, por ejemplo, que en la legislación mexicana "no hay disposiciones específicas para prevenir o invalidar ciertas acciones legales que perjudican la capacidad del país de congelar, asegurar o recuperar bienes sujetos a decomiso." 37

En cuanto a la extinción de dominio, este estudio arroja que dicha figura no fue utilizada en forma activa desde su introducción en el año 2008. Esto, según algunas autoridades colaboradoras al estudio, debido a la falta de capacidad de

\footnotetext{
${ }^{36}$ Red por la Rendición de Cuentas y Centro de Investigación y Docencia Económicas, Hacia una política nacional anticorrupción. Bases para una discusión pública (documento preliminar), México, 2018, p. 152, consultado el 14 de octubre de 2018 en: http://rendiciondecuentas.org.mx/wp-content/uploads/2018/06/PNAAccountWordPressEduHdez.pdf

${ }^{37}$ FATF y GAFILAT, Medidas anti lavado y contra la financiación del terrorismo-México. Informe de Evaluación Mutua, FATF, París, 2018, p. 143. [En línea] consultado el 14 de octubre de 2018 en:

http://www.fatf-gafi.org/publications/mutualevaluations/documents/mer-mexico-2018.html
} 
los fiscales y las restricciones en el alcance de la aplicación a ciertos delitos. Asimismo, expone algunas dificultades que tiene el Servicio de Administración y Enajenación de Bienes para administrar los bienes, debido a su limitada competencia $^{38}$.

Por otro lado, en materia de corrupción es importante mencionar que el tipo penal de cohecho contempla la aplicación en favor del estado del dinero o dádivas entregados a cambio de la conducta u omisión indebida, esto en el Código Penal Federal y en la mayoría de los códigos locales de las entidades. Si bien este producto no fue extraído del erario público en estricto sentido, las conductas desplegadas por tal motivo pueden recaer en graves afectaciones al mismo.

\section{Conclusiones:}

- La recuperación de activos representa una vulneración a la sociedad en su conjunto, por el golpe al adecuado funcionamiento del gobierno y con ello a la ejecución de programas y políticas públicas en diferentes ámbitos, lo que merma el desarrollo de amplios sectores de la población.

- Retornar activos al estado supone una tarea difícil para las autoridades en procuración de justicia. Los costes económicos de la recuperación, lo complejo de su gestión y la facilidad con que los recursos se movilizan en el plano internacional representa una ardua labor de seguimiento.

- El marco jurídico internacional refleja la intención por perfeccionar las modalidades de recuperación de activos y promover la colaboración internacional encaminada a ello, reconociendo la importancia de eliminar fuentes de financiamiento del delito y la necesidad de reparar el daño patrimonial generado.

- Debe adecuarse el orden jurídico a fin de considerar la magnitud del problema de la corrupción en el país. Si bien el decomiso, la declaración de abandono y la extinción de dominio son figuras vigentes en la legislación mexicana, puede ampliarse su ámbito de aplicación para contemplar más tipos penales relacionados con corrupción en casos de extinción de

${ }^{38}$ Ibídem, p. 66. 
dominio, así como definir y ampliar las facultades de las autoridades investigadoras y disminuir las dificultades que representa la búsqueda de la recuperación de activos.

\section{Bibliografía y fuentes consultadas:}

FATF y GAFILAT, Medidas anti lavado y contra la financiación del terrorismoMéxico. Informe de Evaluación Mutua, FATF, París, 2018, p. 143. [En línea] consultado el 14 de octubre de 2018 en:

http://www.fatf-gafi.org/publications/mutualevaluations/documents/mer-mexico-2018.html

Instituto Nacional de Estadística y Geografía (INEGI), "Encuesta Nacional de Calidad e Impacto Gubernamental" [En línea] consultado el 14 de octubre de 2018 en: http://www.beta.inegi.org.mx/proyectos/enchogares/regulares/encig/2017/default.html

La corrupción y los derechos humanos. Estableciendo el vínculo. Consejo Internacional para el Estudio de los Derechos Humanos (CIEDH), 2009, pp. 8-13 [En línea] consultado el 09 de septiembre de 2018 en:

http://workspace.unpan.org/sites/Internet/Documents/UNPAN041206.pdf

Moreno, Moisés, "Política criminal frente a la delincuencia organizada en México", en García, Sergio y Vargas, Leticia (coords.), Las reformas penales en los últimos años en México (1995-2000), IIJ-UNAM, México, 2001, p. 157, [En línea] consultado en el 09 de septiembre de 2018 en:

https://biblio.juridicas.unam.mx/bjv/detalle-libro/131-las-reformas-penales-de-los-ultimosanos-en-mexico-1995-2000

Nieto, Adán y Maroto, Manuel (directores), Public compliance. Prevención de la corrupción en administraciones públicas y partidos políticos. Ediciones de la Universidad de Castilla-La Mancha, Cuenca, 2014, p. 280.

Núñez, Miguel, “Mercado internacional y corrupción”, en Ferré, Juan (coord.), Korupcjia w sektorze prywatnym, Wydawnictwo Naukowe, Varsovia, 2004, pp. 11 y ss.

Red por la Rendición de Cuentas y Centro de Investigación y Docencia Económicas, Hacia una política nacional anticorrupción. Bases para una discusión pública (documento preliminar), México, 2018, p. 152, consultado el 14 de octubre de 2018 en: http://rendiciondecuentas.org.mx/wp-content/uploads/2018/06/PNAAccountWordPressEduHdez.pdf

Transparencia Internacional TI, Índice de percepción de la corrupción, [En línea] consultado el 14 de octubre de 2018 en:

https://www.transparency.org/research/cpi/overview

- Normatividad vigente:

Constitución Política de los Estados Unidos Mexicanos.

Código Penal Federal. 
Código Nacional de Procedimientos Penales.

Ley Federal para la Administración y Enajenación de Bienes del Sector Público.

Ley Federal de Extinción de Dominio.

Asamblea General de las Naciones Unidas, "40/34 Declaración sobre los principios fundamentales de justicia para las víctimas de delitos y del abuso de poder", 1985, [En línea]

http://www.ohchr.org/SP/Professionallnterest/Pages/VictimsOfCrimeAndAbuseOfPower.aspx

Resolución 56/186. "Prevención de las prácticas corruptas y la transferencia de fondos de origen ilícito y lucha contra ellas y repatriación de esos fondos a sus países de origen", 2002, [En línea] consultado el 09 de septiembre de 2018 en:

http://www.un.org/es/comun/docs/?symbol=A/RES/56/186

Naciones Unidas - Oficina contra la Droga y el Delito, "Convención de las Naciones Unidas contra la Delincuencia Organizada Trasnacional y sus protocolos", 2004.

“Convención de las Naciones Unidas contra la Corrupción”, 2003.

Organización de los Estados Americanos (OEA), "Convención Interamericana contra la Corrupción", 1996.

Organización para la Cooperación y el Desarrollo Económicos (OCDE), "Convención para combatir el cohecho de servidores públicos extranjeros en transacciones comerciales internacionales y Documentos relacionados", 1997.

- Criterios jurisprudenciales:

Tesis: 1a./J. 21/2015 (10a.), Semanario Judicial de la Federación y su Gaceta, Décima Época, t. I, abril de 2015, p. 340.

Tesis: P. LXXIV/96, Semanario Judicial de la Federación y su Gaceta, Novena Época, t. III, mayo de 1996, p. 55.

- Normatividad histórica:

Código Penal para el Distrito y Territorios Federales en Materia de Fuero Común, y para toda la República en materia de Fuero Federal, 2 de enero de 1931 http://www.diputados.gob.mx/LeyesBiblio/ref/cpf/CPF_orig_14ago31_ima.pdf

Diario Oficial de la Federación, martes 8 de mayo de 1945, Tomo CL, No. 5, consultado el 14 de octubre de 2018 en:

http://www.diputados.gob.mx/LeyesBiblio/ref/cpf/CPF_ref09_08may45_ima.pdf lunes 15 de enero de 1951, Tomo CLXXXIV, No. 12, consultado el 14 de octubre de 2018 en:

http://www.diputados.gob.mx/LeyesBiblio/ref/cpf/CPF_ref17_15ene51_ima.pdf martes 31 de diciembre de 1974, consultado el $1 \overline{4}$ de octubre de 2018 en:

http://www.diputados.gob.mx/LeyesBiblio/ref/cpf/CPF_ref34_31dic74_ima.pdf miércoles 5 de enero de 1983, consultado el 14 de octubre de 2018 en:

http://www.diputados.gob.mx/LeyesBiblio/ref/cpf/CPF_ref45_05ene83_ima.pdf octubre de 2018 en: miércoles 13 de enero de 1965, Tomo CCLXVIII, No. 10, consultado el 14 de 
http://www.diputados.gob.mx/LeyesBiblio/ref/cpf/CPF_ref21_13ene65_ima.pdf de 2018 en: miércoles 18 de junio de 2008, Primera sección, consultado el 14 de octubre

http://www.diputados.gob.mx/LeyesBiblio/ref/dof/CPEUM_ref_180_18jun08_ima.pdf miércoles 27 de mayo de 2015 , consultado el $\overline{1} 4$ de octubre de 2018 en: http://www.diputados.gob.mx/LeyesBiblio/ref/dof/CPEUM_ref_223_27may15.pdf

- Notas periodísticas:

Milenio (Agencia) "A 10 años de la guerra contra el narco: 100 mil muertos y 30 mil desaparecidos" [En línea] consultado el 09 de septiembre de 2018 en: http://www.milenio.com/policia/10-anos-guerra-narco-100-mil-muertos-30-mildesaparecidos;

Pardo, José Luis, "México cumple una década de duelo por el fracaso de la Guerra contra el Narco", New York Times [En línea] consultado el 09 de septiembre de 2018 en: https://www.nytimes.com/es/2016/09/07/mexico-cumple-una-decada-de-duelo-porel-fracaso-de-la-guerra-contra-el-narco/

Camarena, Jorge, "La economía detrás del narcotráfico", El Economista, [En línea] consultado el 09 de septiembre de 2018 en: https://www.eleconomista.com.mx/politica/La-economia-detras-del-narcotrafico20130108-0178.html

Recibido 17 octubre 2018 Aceptado 18 Noviembre 2018 